\title{
AC 2008-623: A GLOBAL MODEL FOR HIGHER EDUCATIONAL INSTITUTIONS TO INCREASE THE ENROLLMENT OF MINORITY AND INTERNATIONAL STUDENTS
}

\section{Fazil Najafi, University of Florida}

Dr. Najafi is a professor of Civil and Coastal Engineering at the University of Florida. He earned his BSCE from the American College of Engineering, Kabul, Afghanistan, and his BSAE, MS, and $\mathrm{PhD}$ degrees in Civil Engineering from Virginia Polytechnic Institute and State University. He has worked for 35 years in government, industry, and education. Besides teaching during more than 20 years, Dr. Najafi has conducted research, has been a participating member of several professional societies including ASEE, has published numerous refereed and non-refereed articles, and has presented many technical papers to international, national and local organizations.

\section{Dennis Jet, University of Florida}

Dr.Jet is the Dean of International Center at the University of Florida. He was a former embassardor and a schalor with many years of experince.

\section{Nick Safai, Salt Lake City College}

Dr. Nick Safai is the Head of the Engineering Department (which consists of 9 engineering programs: Civil, Mechanical, Electrical, Chemical, Material Science, Environmental, Manufacturing, Bioengineering and Computer Engineering). He is a tenured full professor. He received from Princeton University his Ph.D. in Engineering (Multidisciplinary), also MS in Aerospace, MS in Mechanical, MSE in Civil Engineering, and an MSE in Reservoir Engineering/Water Resources (all from Princeton University), as well as a B.S. in Mechanical Engineering from Michigan State. Prior to joining the academics, Nick worked in industry, where he served as Director of the Reservoir Engineering at Chevron Oil Corporation in California. He has taught both at the graduate and undergraduate levels in engineering science. He has erformed research projects for the Department of Energy (DOE), Department of Defense (DOD), National Science Foundation (NSF) and the Oil Industry. He has authored over 85 technical publications in Technical Journals, Government \& Industry project reports, DOE, DOD and NSF. His research areas of interest have been coupling of Solid Mechanics \& Fluid Flow, 3-D Multiphase Flow in an Unsaturated / Saturated Deforming Porous Medium, Wave Propagation \& Stress Concentration, and Filamentary Composite Materials. 


\title{
A Global Model for Higher Educational Institutions to Increase the Enrollment of Minority and International Students
}

\begin{abstract}
The overall mission of a higher educational institution must include increasing the enrollment of minority and international students within its student population. The population of the United States is very diverse, yet many universities lack diversity within their student population. This paper presents a model that incorporates growth in the number of minority and international students within the existing student population as part of a university's overall mission.

The proposed model focuses on university student enrollment and presents a step-by-step procedure of how to increase the number of minority and international students within the overall student population. To enhance the existing diversity of a university, the model looks at the existing university student population and sets a target number to achieve over a planning horizon. A realistic target number can be established by looking at the existing minority and international student population and the rate of change over the past ten years. A realistic yearly rate can only be established if the university already has an aggressive recruitment and retention program. The success of the model depends on how the university's overall mission treats diversity in its future growth. In the overall growth picture, a diversity strategy should be included with a strong commitment to increase the number of minorities among the student body, faculty and staff. This model includes programs such as recruitment, retention, orientation, and professional development workshops. To increase the number of international students, the model looks at institutional centers such as Lain American studies, International Food and Agriculture Science studies, joint university research institutes, the Peace Corps, Centers for European, Asian, Middle Eastern, and African studies, as well as study-abroad programs, ambassador programs and recruitment, and orientation and retention of international students and scholars.
\end{abstract}

Allocation of resources plays a vital role in the implementation of the diversity model. The model includes two parts, one for each of the undergraduate and graduate populations. The programs need to be actively incorporated and coordinated within each department of the various colleges under the main umbrella of the university's overall mission. The program coordinators work as a team in competitive cooperation to successfully implement the mission for diversity under the goals of the institution of higher learning. The team members' aggressiveness, motivation, creativity, interpersonal skills, financial support and recognition of the importance of diversity within the student population play a vital role in the successful implementation of this program. The model includes an assessment feature and provides a mechanism that gives feedback from all colleges within the university for continuous monitoring of program assessment and improvement. 


\section{Introduction}

Mission of an institution of higher education (IHE) should include diversity in admitting Blacks, Hispanic, International students and Other Minorities (BHIOM). According to the National Science Foundation data only a fraction of the black students who earn a doctorate degree is hired as a university professor. Blacks make up 3 percent of the legal field, 4 percent of college faculty and 5.2 percent of entertainers, writers, and

professional athletes in the U.S. ${ }^{1}$ According to Raspberry, the home of the average white kindergartener has 93 books and the average black child has less than half as many. ${ }^{2}$ Recognizing these facts, it is essential for every IHE to allocate a portion of their resources in the form of scholarships and fellowships in admitting BHIOM in their institutions. This paper presents a model that may be used by an IHE to enhance its existing graduate and undergraduate minority enrollment. The model can be utilized for both short and long-range planning. To achieve diversity, the IHE strategic plan should have a target year that shows the existing enrollment of BHIOM students as well as the projected future trend. The model suggests that an undergraduate (UG) and graduate (G) minority and international programs must be established first. The IHE organizational flowchart should include the UG \& G programs including BHIOM elements. Each year, international students contribute billions of dollars to the U.S. economy through their tuition and fees and living expenses. In 2006/2007 the net contribution to the U.S. economy by foreign students and their families was $\$ 14,499,000,000.00^{3}$.

Therefore, dedicated and committed efforts are needed throughout the university colleges and departments to actively participate in the implementation of BHIOM model. The success of the model depends on aggressive recruitment, retention, and orientation through planned professional development workshops. A workable model can be achieved by placing the UG \& G mission under the university's overall mission. The university's mission should have the ability to continuously deliver productive students to the society. To keep up with diversity, offering of fellowships and financial aid is needed to attract qualified under-represented social/ethnic groups. Such a mission will only be accomplished through full dedication of administrators, faculty and staff. Each department within IHE colleges must participate in vigorous recruitment of top quality UG \& G minority students, maintaining and hiring diversified top administrators and staff with faculty engaged in state-of-the-art teaching, research and service. This paper presents steps needed to enhance BHIOM enrollment. Finally, there is a mechanism that will provide feedback from all colleges within the institution for the continuous assessment and improvement of overall programs. Student academic advisors play a vital role in supporting and retaining students until they complete their education.

\section{The Model}

Figures $1 \mathrm{a}$ and $1 \mathrm{~b}$ together present a proposed IHE diversity model. The model looks at the existing total number of minority students (MS) and projects MS growth over a span of time. The MS students in this study include all of the BHIOM with separate counting of the number of blacks, hispanics, international and other minority students. The BHIOM students growth is achieved through aggressive recruitment and retention under each category of BHIOM students . 
The model looks at both UG \& G programs and incorporates them under the mission of IHE. Both UG \& G programs are linked and to succeed they should be enhanced at the same level of effort with proper allocation of resources. The curriculum components are important in supporting student retention. There should be BHIOM student support services including tutoring, counseling, career advising, and employer encouragement. At the graduate level, there are many BHIOM students of superior ability who demonstrate financial need and plan to pursue a $\mathrm{PhD}$ degree in a designated area of national need. The IHE Diversity Model should offer fellowships to such students and increase their numbers by aggressively promoting recruitment, retention and orientation of those talented students from traditionally underrepresented backgrounds. 

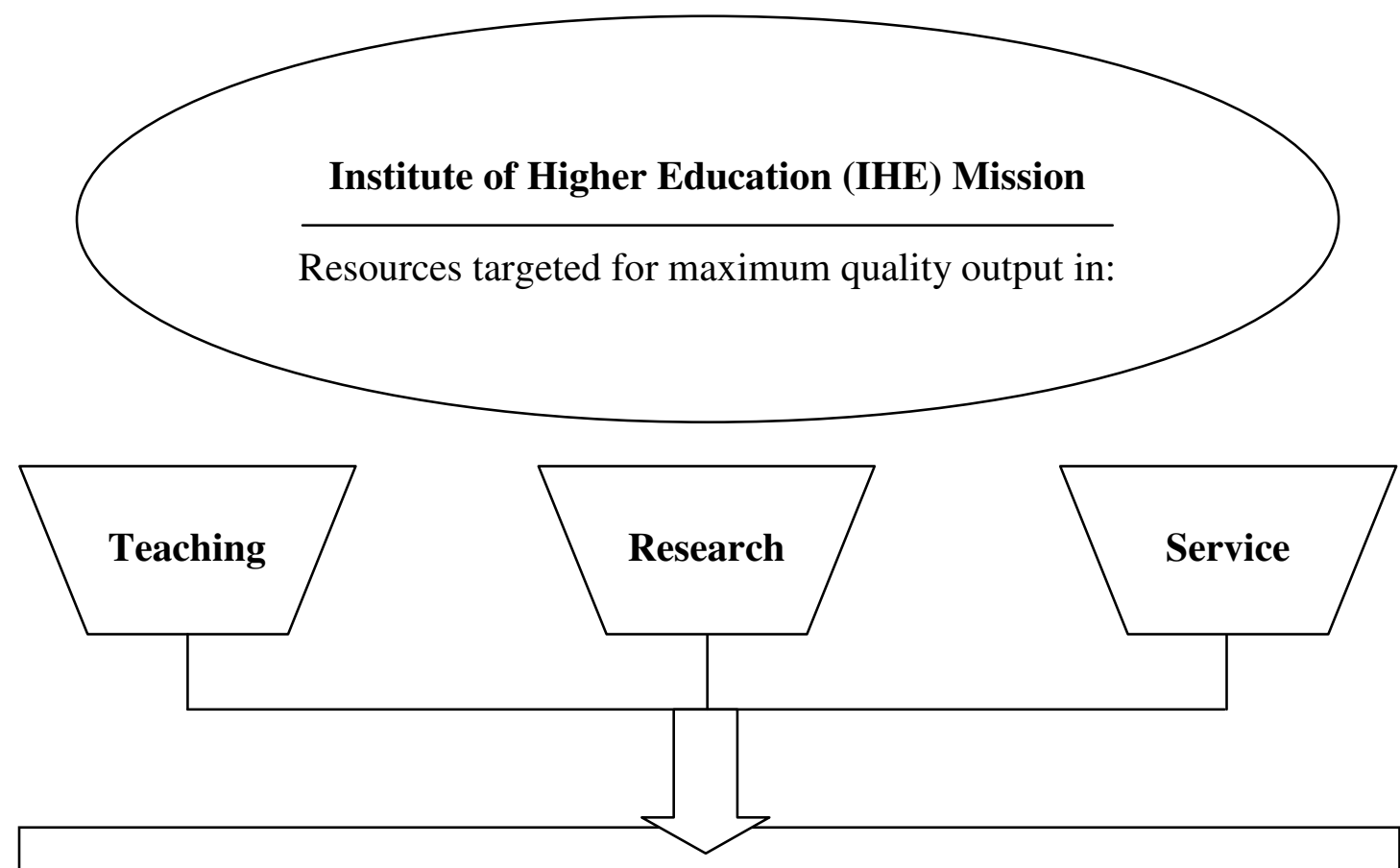

Increase the overall UG \& G enrollment of BHIOM by 15000 students over the next decade

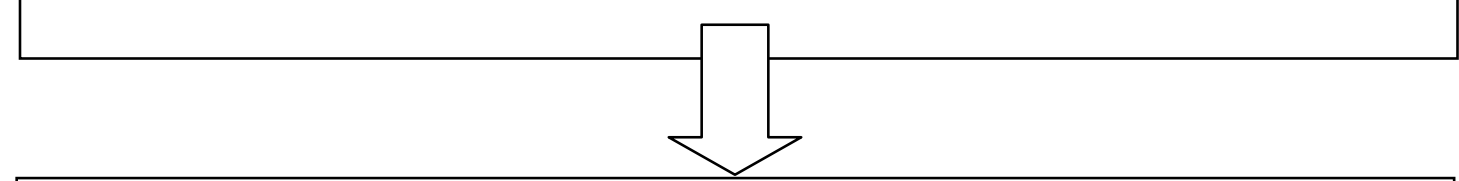

Establish UG \& G BHIOM Program Mission

To enhance the development and implementation of programs for UG \& G BHIOM by promoting recruitment, retention, orientation and professional development workshops

Increase BHIOM UG enrollment by 10000 students over the next decade Increase BHIOM G enrollment by 5000 students over the next decade

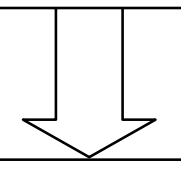

Accomplish UG \& G programs by allocating resources and promoting, recruitment, retention, orientation, and professional development workshops

Figure 1a. First part of a proposed model of the IHE Mission to enhance the overall undergraduate and graduate enrollment of BHIOM students 


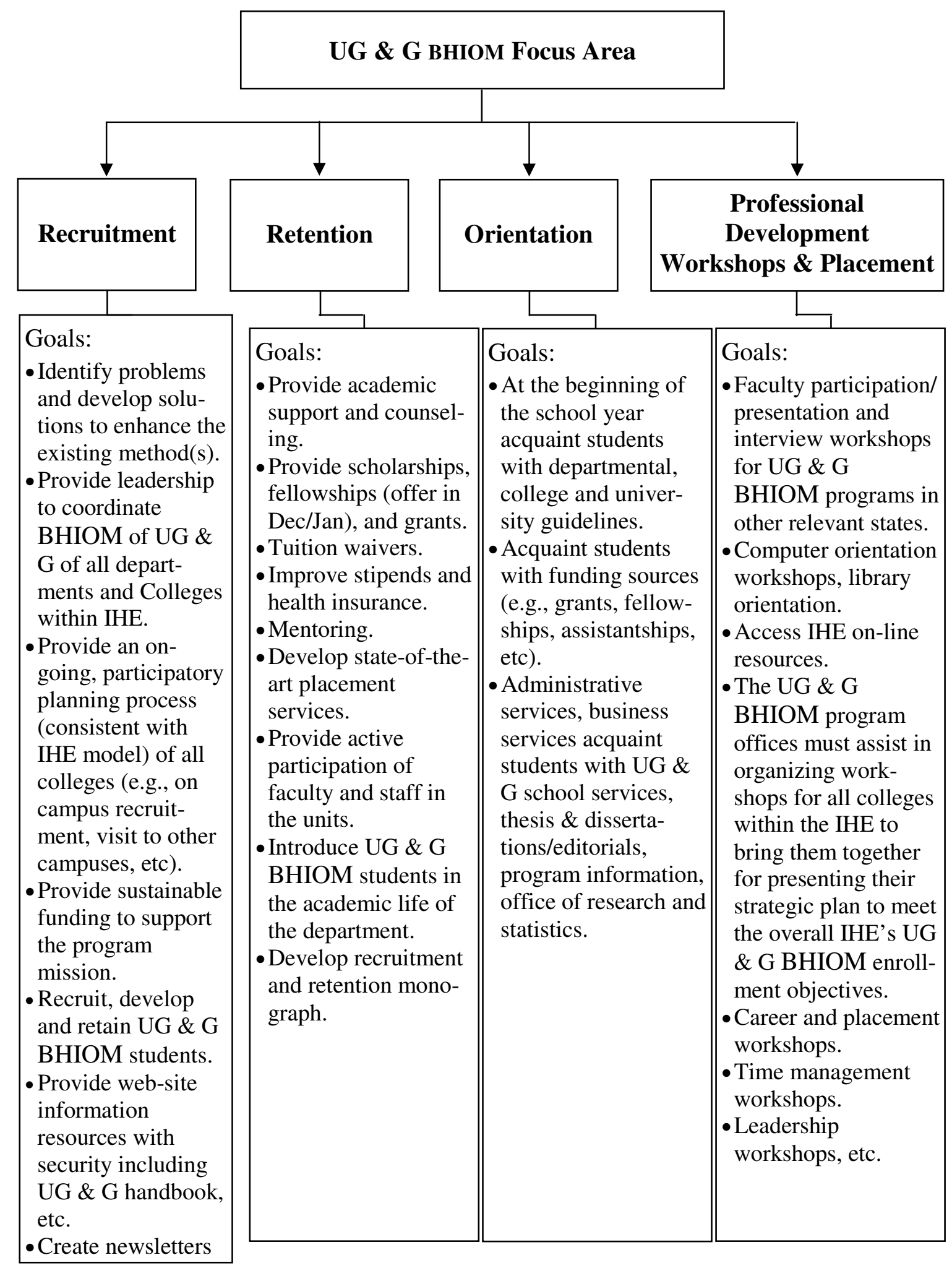

Figure 1b. Second part of a proposed model of the IHE Mission to enhance the overall undergraduate and graduate enrollment of BHIOM students 


\section{Steps to Achieve IHE's Objectives}

The first and utmost important step is to develop a strategic plan within the IHE. All colleges and departments within a typical IHE must develop strategic plans that are consistent with the IHE's overall strategic plan. The IHE strategic plan can be successful only if the strategic plans of the colleges and departments are in full support of the IHE's strategic plan. Each college and its departments must work closely with the UG admissions office and the dean of the graduate school to identify, recruit and retain qualified underrepresented graduate students in line with the goals and objectives of the IHE program. The IHE must allocate certain numbers of fellowships to each college. From the fellowship pool, each college allocates a certain number of fellowships to each of their departments. This process assists each department in using their own recruitment process in conjunction with their college and university recruitment program to attract graduate minority students. The IHE must develop an aggressive recruitment, retention and orientation program. Figures $1 \mathrm{a}$ and $1 \mathrm{~b}$ present an IHE model strategic plan that provides a basis for each department to develop and enhance their recruitment program under the IHE's main umbrella. Each department within a college can strengthen its undergraduate recruitment efforts through its association with K-12 and industry involvement, particularly for recruitment and retention efforts. In this process, faculty support and dedication are essential toward accomplishing BHIOM student recruitment and retention. Hypothetical numbers are used in Figures 1a and 1b. The actual number for each student category can be calculated by each college and the total can be placed in the model above for a realistic IHE BHIOM projection. The student enrollment for each category can be summed and projected. From historical data a growth rate can be calculated for each student category.

\section{Evaluation Plan}

The goals of the IHE program are to increase the number of qualified graduate and undergraduate BHIOM applicants. And particularly for US minority students, attention should be given to those minority students of traditionally underrepresented backgrounds. Each department within the college should closely work with the offices of the IHE Graduate and Undergraduate Minority Assistant Dean(s) and international student dean to aggressively recruit students from each category. A typical pattern of recruitment and stages for student selection include:

- Defining the pool of qualified individuals

- Recruiting applicants

- Screening out applicants who do not meet minimum qualifications

- Selecting the most acceptable from among all qualified applicants

- Persuading recruits to accept offers to pursue careers or advanced study in a field

- Training and socializing recruits

- Providing opportunities for successful recruits to make a smooth transition from training into meaningful employment trajectories. 
The above process can be used by each department to recruit existing qualified minority and international students within the department as well as from other universities. Vigorous minority recruitment, backed by financial assistance such as fellowships, can yield improvements in each department's enrollment, retention, and graduation rates. Figure $1 \mathrm{~b}$ presents goals for recruitment, retention, orientation and placement. An institution can establish its objective to increase graduate minority students enrollment by a certain number over the next decade. Considering the current minority graduate student enrollment trend, each department will use their existing allocated number of fellowships and provide support to a certain number of new graduate and undergraduate minority students over the next decade. Increasing the enrollment of talented US graduate students from traditionally underrepresented backgrounds would definitely meet the set objective of any IHE diversity program.

\section{Assess the Effect of Offering IHE's Fellowships to Minority Students}

The purpose of the IHE diversity program should be to realize and understand barriers to academic mobility and to identify effective strategies to increase the flow of international students and US underrepresented racial/ethnic groups. The departments within each college should be able to successfully achieve the IHE goal by recruiting and increasing the number of assistantships to new graduate students of superior ability who demonstrate financial need and plan to pursue $\mathrm{PhD}$ degrees in a designated area of national need. The IHE's fellowship should be offered to those qualified persons of different racial and ethnic backgrounds, genders and ages and persons with disabilities. With the help of the IHE fellowship program, each department's retention and graduation rates will be significantly improved. Furthermore, it will have a large impact on the expansion of the overall candidate pool.

\section{Process and Product Evaluation}

This process includes working closely with the Deans of the UG and G minority and international programs to recruit qualified students. After a successful recruitment process, the evaluation questions become critical to the successful completion of the education of the UG and G students. Once students are enrolled in the IHE's fellowship program, the designated course advisors in each department are to meet with the candidates on a regular basis to evaluate the student's educational activities and progress. Each candidate is to have a separate file including the list of courses for the duration and completion of his/her BS, MS, and PhD program. On a regular basis, the designated professor is to meet the IHE's Fellowship Program Directors for both UG and G students. The professor is then to brief the program director on the status of the student's progress. Accordingly, the director of the fellowship program is to update his management plan regularly.

\section{Evaluation Measures}

An advisor, who is also a student mentor, is to be assigned to each student. A mentormentee relationship is then established. A mentor shares valued skills to improve the 
mentee's marketability. The mentor will work closely with the mentee to broaden the mentee's educational perspective, support the mentee's academic and social endeavors, foster activities in academic organizations and other leadership roles and consistently serve as an available resource ${ }^{4}$. Data, such as in Table 1 , enable student advisors to assess a student's progress and provide complete assessment reports to the IHE Fellowship Program Directors.

Table 1. Typical List of Courses for a Graduate Student Pursuing a Master's Degree

Name Robert

Area of Study PUBLIC WORKS ENGINEERING

Committee Chairman DR. FAZIL T. NAJAFI

Expected Date of Graduation Fall 2003
SN $\quad 9999-12345$

Degree Sought MS

Option: Report

Thesis

\begin{tabular}{||l|l|c|c|c||}
\hline $\begin{array}{l}\text { Course } \\
\text { Number }\end{array}$ & Course Title & Term & $\begin{array}{l}\text { No. of } \\
\text { Credit }\end{array}$ & Grade \\
\hline SUR 6037 & Topics in GIS & Fall 05 & 03 & B+ \\
\hline CCE 5405 & Construction Equipment \& Procedure & Fall 05 & 03 & A \\
\hline CCE 5035 & Construction Planning\&Scheduling & Fall 05 & 03 & A \\
\hline CGN 5606 & Public Works Management & Fall 05 & 03 & A \\
\hline CCE 6037 & Civil Engineering Operation I & Fall 05 & 02 & B+ \\
\hline CES 5607 & Behavior of Steel Structure & Spr. 06 & 03 & A \\
\hline CGN 5135 & Project Optimization \& TQM & Spr. 06 & 03 & A \\
\hline CGN 5605 & Public Works Planning & Spr. 06 & 03 & A \\
\hline SUR 6395 & Topic in GIS & Spr. 06 & 03 & B+ \\
\hline ACG 5005 & Financial Accounting & Sum 06 & 02 & A \\
\hline CGN 6905 & Special Problems in Civil Engineering & Sum 06 & 02 & A \\
\hline
\end{tabular}

\section{Data Collection Procedures}

The IHE Fellowship Program Directors are to develop a spreadsheet including each candidate's name, gender and ethnic background, e.g., American Indian or Alaskan, Asian or Pacific Islander, African American, Hispanic American, person with disabilities, international students from different countries and other. Other developed spreadsheets are to include course lists of candidates with possible graduation dates, work schedules, regular meeting schedules, work progress on a daily, weekly, monthly and semester basis. This type of data collection procedure is very effective in retaining and evaluating a student's overall academic standings. Students and advisors must be responsible for developing assessment data that is updated regularly and kept by all parties involved in the assessment program. 


\section{Applicants' Accessibility to Their Data Record}

Each UG and G student has full access to his or her work progress. Students are to maintain their work progress records (e.g., courses, grades, etc., see Table 1). Similar assessment tables are also to be developed to reflect the student's research work progress. From these tables, applicants are able to analyze their work, adjust and make improvements on a regular basis, and report to their advisors. Reports can regularly be collected by a student advisor and submitted to the IHE's Fellowship Project Directors. The directors evaluate the reports, make necessary comments and return to the student's advisors.

\section{Time-line Chart}

A table can be prepared showing student name, admission date, semester attended (e.g., Fall, Spring, Summer). Such a table can be compared with another table (work progress) showing student name, list of activities, person responsible, start date, completion date and status. These types of tables, including Table 1, for each candidate should provide key evaluation processes and benchmarks reflecting each candidate's overall progress.

\section{A Case Example of the College Of Engineering at the University of Florida}

The model above was partially implemented not at the university level but at the college level. The college of engineering went aggressively through a process of recruitment, retention, orientation, and professional development and placement. Figure 2 presents data on the engineering students in general (blue bar) and STEPUP engineering students (purple bar) from freshmen year (Fall 1996) to senior year and graduation (Fall 2000 and Fall 2006). In this figure, STEPUP students include Blacks, Hispanics, International and Other Minority students. It can be seen that the purple bars show higher rates of graduation as compared to the blue bars. This is a positive example how an institution can implement aggressively the process as presented in Figure $1 \mathrm{~b}$. 


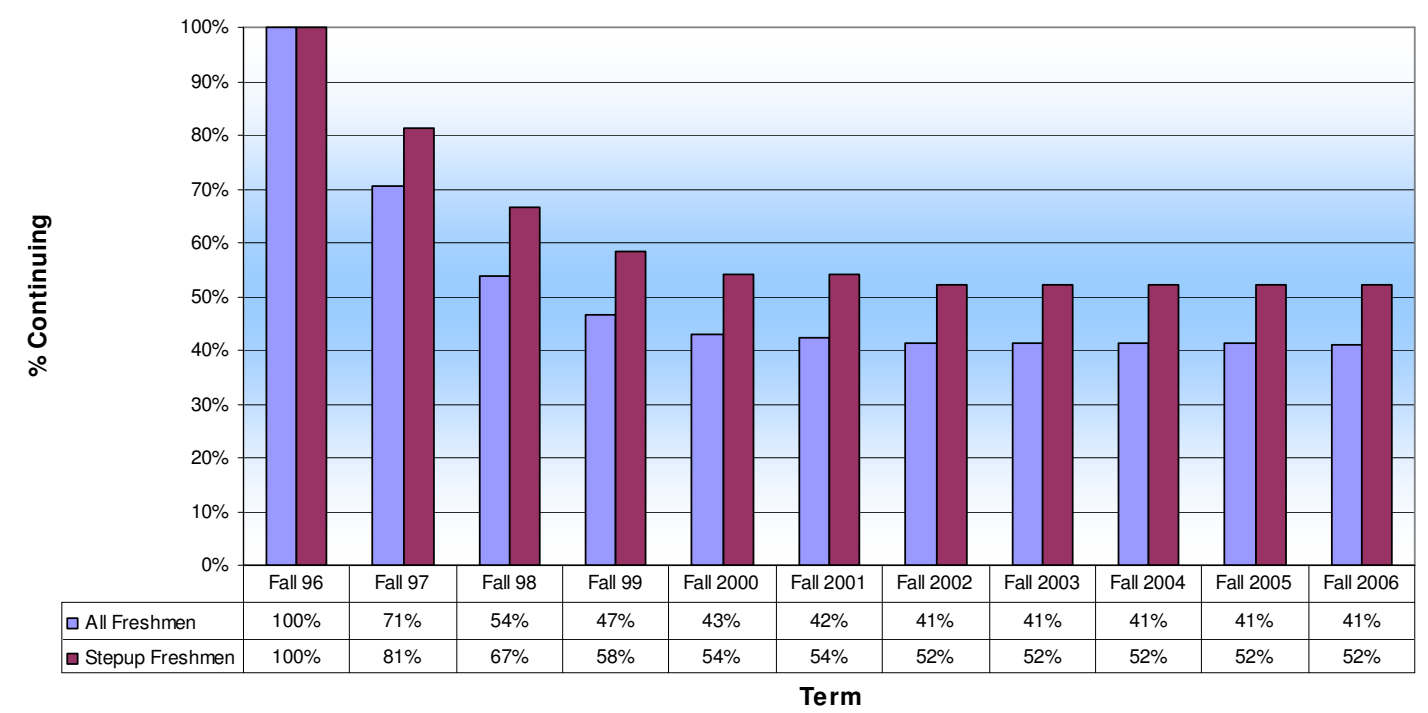

Figure 2. All freshmen and STEPUP students from first year to graduation at the College of Engineering, University of Florida

\section{Conclusion}

In most IHE's in the U.S., the enrollment of persons with different racial and ethnic backgrounds has been low for the past ten years. A typical model is presented in this paper. The model is flexible and can be used by any IHE to increase the enrollment of UG and G BHIOM students. To make the model work, the IHE needs to obtain a ten-year projection and target certain numbers of UG and $\mathrm{G}$ BHIOM students by looking at existing numbers, and should allocate resources and provide fellowships for qualified students. Student advisors play a vital role in retaining and keeping track of students' academic progress and making sure that they complete their study program and graduate within the specified time period. The department should develop videos on faculty development to educate faculty for active participation in recruitment and retention efforts. Student advisors must take responsibility for advising students throughout their academic careers. The IHE program directors must require regular academic progress reports of students from advisors. If students are having any academic problems, advisors must develop a strategy with the students to resolve problems and assist them in their academic career. It is clear that diversity efforts pay off both in the short-term and long-term. Graduating students of IHE will become the next generation of academic and business leaders throughout the nation and the world. The process of recruitment and retention of minority students through support and mentoring requires the dedicated efforts of faculty and administration. Minority and international students gain lifelong experience that will shape them as society's role models, particularly from mentor-mentee relationships, and in this way, they will begin to contribute back to the society completing the continuous process. In the $21^{\text {st }}$ century, when the United States is becoming increasingly 
diverse and the working world is becoming increasingly globalized, it is essential for all IHE's to create an environment that welcomes students, faculty and staff of all races, nationalities, and religions. The model proposed here should help the efforts of IHE's with the recruitment and retention of students, assisting them in a career that will make a difference. The case study of the college of engineering at the University of Florida is a positive indication of using resources in a manner described in Figure 1b. The study is definite implementation of model as presented in this paper. It is important to keep such strategy in mind and implement it using resources to enhance Blacks, Hispanics, International and Other Minority students.

\section{Bibliography}

1. The Gainesville Sun, a local newspaper, Gainesville, Florida, Nov. 17, 2003.

2. The Gainesville Sun, a local newspaper, Gainesville, Florida, Oct.14, 2003.

3. http://opendoors.iienetwork.org/?p=113748, accessed January 4,2008.

4. University of Florida, "Minority Mentor Program: 2002-2003 Handbook," Gainesville, Florida, 2002.

\section{Acknowledgment}

The model idea came from reading "The University of Florida Strategic Plan," developed in August 2002 by Dr. Charles E. Young, then President of the University of Florida. 